\title{
PSYCHOLOGICAL MODELS FOR ATTITUDINAL AND PERSUASION CHANGES IN CONSUMER BEHAVIOUR
}

\author{
L. Spasova*, Zh. Gundasheva \\ Department of Social Sciences and Business Language Training, Faculty of Economics, \\ Trakia University, Stara Zagora, Bulgaria
}

\begin{abstract}
The present study explores psychological models for changing consumers' attitudes under the influence of advertisements in young people of 18 to 25 years of age.

The aim of the study is to establish the influence of the advertisements of mobile phone operators on the attitudes, consumer thinking and behaviour of youth with respect to mobile products and services. The following tasks were set:

- To study the advertisements of mobile phone operators in Bulgaria

- $\quad$ To set a theoretical frame on consumers' attitudes

- To determine the models of attitudinal change and persuasion

- To perform correlational analyses of statistically significant factors

The methods used to achieve these tasks are the following: conducting two subsequent surveys on the same respondents regarding their behavior before, during and after exposure to advertisement; holding individual interviews with random young respondents.
\end{abstract}

Key words: advertisement, influence on youth, publicity media, mobile companies.

\section{INTRODUCTION}

At present, businesses are developing intensively due to the constant structural changes in world economy. This leads to building new business communications using contemporary information technologies. Mobile phone operators in Bulgaria and abroad offer products and services which incite the interest of the individual consumer, as well as of potential business partners. Advertizing plays a key role for the activity of mobile companies, whose persuasive impact is studied by researchers in terms of its short-term or long-term effects. The advertising strategies and aims are projected in the mind of the consumer, therefore the aspiration of modern specialists on publicity communications is to explore human behavior, consumer thinking, as well as consumer attitudes.

\footnotetext{
*Correspondence to: Lyubomira Venkova Spasova, Department of Social Sciences and Business Language Training, Faculty of Economics, Trakia University, Stara Zagora, Bulgaria,e-mail: liubomira1975@abv.bg
}

\section{CONSUMER ATTITUDES}

The term attitude is present in different fields of science, such as psychology, sociology, communications, publicity, etc. because it is related to the analysis of human behavior. The way in which we process information depends on our attitudes. When determining the essence of attitudes we can observe considerable differences. Some authors emphasize the cognitive elements of attitudes, while others prefer the emotional. In the last decades' authors are convinced that both types are very important for the advertisement's impact [4]. In general, attitudes are defined as the tendency to react in a certain way to given questions, or events, or "a relatively stable primary internal direction, or predisposition of an individual to a certain type of reaction" [3]. According to $\mathrm{B}$. Minchev, attitude is "a subconscious form of stimulating the psycho behavioral activity of an individual, which has been acquired through individual experience and is incited by a certain type of situations". [3] Therefore, attitudes can be defined as inciting habits and routines whereas their 
stimulating effect is triggered automatically in a given situation.

Another key element is emotional attitudes, which are habits for experiencing certain emotions in given circumstances, e.g. the pleasure at the thought of a new mobile phone. Minchev also refers the above mentioned attitudes to the attitude components related to attention [7], which lead consumers' preference for certain goods and services. For instance, if the consumer of goods and services of a certain company thinks they have been provided with reliable information, then they will show trust to the products and services of this same company. Therefore, this reliability determines the building of trust in that company, which will rule consumers' behavior in various situations.

A similar concept was defended by the authors of Effective Public Relations S. Cutlip, A. Center and G. Broom [2] who studied different types of audiences in the process of creating public opinion. They defined attitude as "multilayered situational predisposition or preference to a certain object". According to the same authors, attitudes "predispose individuals to respond in a certain way to specific objects" in different situations on the basis of a given life experience. It becomes clear that researchers are unanimous in their definitions, because forming an attitude is always related to a stimulus, which challenges it, and also determines the behavior of an individual. Therefore, the concept of influence includes mechanisms of impact on consumers' attitudes, whilst an attitude conception is being developed.

Crespi uses the expression "attitudinal systems" for what other authors call attitudes [1]. He thinks that attitudinal system is composed of four components:

- $\quad$ Evaluative frameworks for comparison (values and interests)

- Cognitive abilities (knowledge and beliefs)

- $\quad$ Attachment (feelings)

- Intentional actions (behavioral

intentions).

Other two researchers - Philip Zimbardo and Michael Leippe [10] who have tackled the problems of attitudes also use the term "attitudinal system" when uniting four components: knowledge, affect, intention for action, and behavior. Each attitude is composed of a cognitive component
SPASOVA L., et al.

(knowledge), which includes knowledge and beliefs, affective component - feelings and emotional reactions, behavioral component - a decision or intention for action, and behavior itself, or the real actions, which are being undertaken. The presumption that consumers' attitudes, respectively attitudinal systems, determine consumers' behavior, makes them extremely important for realizing the study on the persuasive influence of publicity [9]. To determine consumers' behavior, researchers have created several basic models through which consumers' attitudes are being investigated.

\section{MODEL FOR ATTITUDINAL CHANGE}

At the basis of persuasion lies human attitude, so the processes of attitudinal change should not be underestimated. Relevant to this is the so-called Yale model for attitudinal change [10] in which three main components have been singled out - communication source, communicatioin character and audience character. This method does not clarify in what cases and in what relation to apply the above mentioned three components. This necessitates the development of a new model which will build on the previous one and will establish the mechanisms of influencing different types of communication.

\section{ELABORATION LIKELIHOOD MODEL OF PERSUASION}

Attitudinal change involves a process of persuasion [6], therefore at the end of the $20^{\text {th }}$ century Robert Petty and John Cacioppo [10] worked on the indicated problem. They proposed the so-called Elaboration Likelihood Model of Persuasion, according to which persuasion is achieved through a central (direct) and peripheral (indirect) routes. The relevant model can give a clearer idea about the mechanisms of persuasion by suggesting two routes of influence.

The central route of persuasion [9] involves careful listening and elaboration on the arguments. Long-term attitudinal change can be achieved through higher motivation in arguments and continuous influence. Soon behavioral changes are observed. The second route of influence is the peripheral [9], which is used when the public do not listen to the arguments. Here an important role is played by the peripheral signals, such as the length of the message (the longer the more persuasive), the communicator's expertise (authority), the attractiveness of the communicator, etc. 
Table 1.Model of Petty and Cacioppo [9].

\begin{tabular}{|l|l|l|l|}
\hline Influence route & Public & Process & Power \\
\hline Central route & $\begin{array}{l}\text { Analytically inclined } \\
\text { and sufficiently } \\
\text { motivated public }\end{array}$ & $\begin{array}{l}\text { Considerable efforts for } \\
\text { persuasion were } \\
\text { exerted: elaboration, } \\
\text { agreement or counter- } \\
\text { arguments }\end{array}$ & $\begin{array}{l}\text { Serious arguments } \\
\text { provoke long-term } \\
\text { attitudinal change }\end{array}$ \\
\hline Stimulant & Stimulant & Stimulant & Stimulant \\
\hline (message) & (message) & $\begin{array}{l}\text { (message) } \\
\text { (message) }\end{array}$ \\
\hline Peripheral route & $\begin{array}{l}\text { No efforts for } \\
\text { persuasion were } \\
\text { anplied: long message } \\
\text { and attractive } \\
\text { communicator }\end{array}$ & $\begin{array}{l}\text { Peripheral signals change } \\
\text { temporary and largely } \\
\text { unstable attitudes }\end{array}$ \\
\hline
\end{tabular}

Source: Myer, D., Social Psyhology, $7^{\text {th }}$ edition, McGraw-Hill, Boston. 2002, p.290.

The methodology for this type of studies may be different, but it aims to establish what the "degree of accessibility of attitudes" is [9]. In relation to their accessibility the following components are monitored: human beliefs and thoughts, different feelings and emotional reactions, decisions and intention for action in a certain way, as well as the relevant actions. From the said above it becomes clear that the peripheral route of persuasion offers a possibility to use social, as well as psychological features of consumer behavior, because attitudinal change is a complex social and psychological process. For organizations and for mobile operators in particular, not attitudinal change, i.e. the element of persuasion, but the use of attitudes, i.e. the element of influence gives a specific behavioral result. Therefore, in publicity communication bi-componential persuasive influence is used: the process of persuasion and the process of influence [6].

\section{MODEL OF PERSUASIVE INFLUENCE}

The Model of persuasive influence developed by Ch. Hristov [6] may explain the direct route of influence which brings actual results. Advertisement is the most conspicuous representative of communication technologies in which manipulative actions are allowed because its end is to acquire a certain product. The main components of the Model for persuasive influence presented in this study are essential for the use of different techniques in the advertisements of Bulgarian mobile phone operators.

Table 2. Model of persuasive influence [6] (cited from Ch. Hristov, 2008).

\begin{tabular}{|l|l|l|}
\hline $\begin{array}{l}\text { Stimulant (advertising } \\
\text { message) }\end{array}$ & $\begin{array}{l}\text { Persuasive influence (deficit or } \\
\text { growth creation, use of euristic } \\
\text { thinking and euristic behavior, } \\
\text { dissonance creation, } \\
\text { conformism) }\end{array}$ & $\begin{array}{l}\text { Reaction (consumers' behavior, } \\
\text { panic, contagiousness, } \\
\text { submissiveness, discrimination, } \\
\text { sexism, etc.) }\end{array}$ \\
\hline
\end{tabular}

Source: Hristov, Ch. Persuasion and Influence., Sofia, 2008, p.66

\section{EXTENDED MODEL OF PERSUASIVE} INFLUENCE

The present publication is part of a large-scale investigation with empirical studies on the persuasive influence of advertisement. This model is expected to outline some of the possible reactions to different respondents, as well as to establish the main dependencies determining behavioral changes in targeted groups.

The Extended model of persuasive influence gives a clear idea for the sequence of influences which may be made through a director peripheral route. The moment of distraction is always taken into consideration when no reaction or purchase is observed. The main task is to observe the specific moments of influence in youth aged 18 to 25 , who are using mobile services most actively and are inclined $t$ follow fashionable trends. The conducted survey leads to the following hypotheses:

Hypothesis 1: Consumer attitudes are completely stable and the possibility for influencing and changing them is very hard to achieve.

Hypothesis 2: The change in persuasion of youth reflects on the change in their behaviour when using products and services of mobile operators in Bulgaria. 
SPASOVA L., et al.

Table 3. Extended model of persuasive influence - main types of reactions to publicity messages.

\begin{tabular}{|c|c|c|c|c|}
\hline $\begin{array}{l}\text { Type 1: } \\
\text { Stimulant } \\
\text { (publicity } \\
\text { message) }\end{array}$ & $\begin{array}{l}\text { Perception and } \\
\text { interaction with } \\
\text { advertisement }\end{array}$ & $\begin{array}{l}\text { Persuasive influence } \\
\text { (triggering events) }\end{array}$ & $\begin{array}{l}\text { Reaction- } \\
\text { interpersonal } \\
\text { information } \\
\text { exchange with } \\
\text { respect to } \\
\text { advertisement } \\
\text { (presence of } \\
\text { latent attitudes) }\end{array}$ & $\begin{array}{l}\text { Result - } \\
\text { purchase or use } \\
\text { of services is } \\
\text { not } \\
\text { accomplished }\end{array}$ \\
\hline $\begin{array}{l}\text { Type 2: } \\
\text { Stimulant } \\
\text { (publicity } \\
\text { message) }\end{array}$ & $\begin{array}{l}\text { Perception and } \\
\text { memorization of } \\
\text { the } \\
\text { advertisement }\end{array}$ & 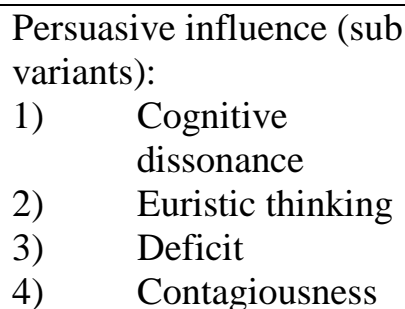 & $\begin{array}{l}\text { Reaction - } \\
\text { partial } \\
\text { persuasion } \\
\text { (building initial } \\
\text { attitudes) }\end{array}$ & $\begin{array}{l}\text { Result- single } \\
\text { purchase or use } \\
\text { of service }\end{array}$ \\
\hline $\begin{array}{l}\text { Type 3: } \\
\text { Stimulant } \\
\text { (publicity } \\
\text { message) }\end{array}$ & $\begin{array}{l}\text { Perception and } \\
\text { distractedness } \\
\text { after } \\
\text { advertisement } \\
\text { impact }\end{array}$ & $\begin{array}{l}\text { Persuasive influence of } \\
\text { analogues of competitive } \\
\text { organizations }\end{array}$ & $\begin{array}{l}\text { Reaction - } \\
\text { persuasion } \\
\text { (building } \\
\text { cognitive, } \\
\text { emotional and } \\
\text { connotative } \\
\text { attitudes) } \\
\end{array}$ & $\begin{array}{l}\text { Result - } \\
\text { subsequent } \\
\text { purchasing or } \\
\text { use of services }\end{array}$ \\
\hline $\begin{array}{l}\text { Type 4: } \\
\text { Stimulant } \\
\text { (publicity } \\
\text { message) }\end{array}$ & $\begin{array}{l}\text { Perception and } \\
\text { forgetting the } \\
\text { advertisement }\end{array}$ & $\begin{array}{l}\text { Persuasive influence of } \\
\text { competitive analogues } \\
\text { (conformism) }\end{array}$ & $\begin{array}{l}\text { Reaction - new } \\
\text { persuasion } \\
\text { (building of } \\
\text { attitudinal } \\
\text { system) }\end{array}$ & $\begin{array}{l}\text { Result - no } \\
\text { purchase. } \\
\text { Competitor's } \\
\text { services are } \\
\text { chosen. }\end{array}$ \\
\hline
\end{tabular}

\section{EMPIRICAL OBJECTS STATISTICAL SAMPLES}

The subjects of the present report are 300 young people between the ages of 18 and 25, employed or students in Bulgarian universities - Sofia University, Plovdiv University and Trakia University. Their attitudes to mobile phone operators in Bulgaria presented as an object of the study have been diagnosed with surveys at two stages. The selection is realized randomly, whereas the only requirement for inclusion is whether they have used or are still using products or services of Bulgarian mobile operators. Advertisement influence on target groups has been considered through various publicity media reaching relevant consumers. The experimental design is intra-group, because all studied persons have been subjected to the same conditions. In order to perform the analyses for each demographic characteristic, the studied individuals have been divided into groups. The participants have been divided into three groups according to their age: the first one was $18-20$ years -129 people, or $43 \%$, the second group $-21-24$ years -128 people, or $41 \%$, and the third group - over 25 years - 43 people, or $16 \%$. The respondents in the survey for this age group are the fewest. The correlation between the ages of the participants is presented in the following table. (Table 1)

Table 4. Percentage distribution of respondents by age.

\begin{tabular}{|l|l|l|}
\hline Age of respondents & Percentages & Number \\
\hline Over 25 years & $16 \%$ & 43 \\
\hline $21-24$ years & $41 \%$ & 128 \\
\hline $18-20$ years & $43 \%$ & 129 \\
\hline
\end{tabular}

Another demographic factor is education, which has led to the formation of three groups (Table 1): higher - 38 people, secondary - 259 people and elementary, or the lowest educational level 3 people. Each studied person falls into a single category which presupposes the characterization of questions as independent samples. For the largest group - secondary school level - the respondents have been divided into three groups according to their age or gender. 
Table 5. Distribution by educational degree.

\begin{tabular}{|c|l|l|l|l|}
\hline Education & Number & Percentages & Valid percent & $\begin{array}{l}\text { Cumulative } \\
\text { percent }\end{array}$ \\
\hline Primary & 3 & 1,0 & 1,0 & 1,0 \\
Secondary & 259 & 86,3 & 86,3 & 87,3 \\
Higher & 38 & 12,7 & 12,7 & 100 \\
Total & 300 & 100 & 100 & \\
\hline
\end{tabular}

Initial tests for checking the methodology structure have been conducted through the application of factorial analysis to the separate statements indicated as answers to the questions measuring less or more highly significant factors. This statistical method in general aims to highlight the factors which are common for a multitude of variables including correlations. The number of respondents amounts to 300 for both surveys. The biggest number belongs to Telenor subscribers -121 persons, or $40.3 \%$, followed by A1 -88 persons, or $29 \%$. Vivacom reaches 75 persons, or $25 \%$, while "other" is chosen by 2 respondents, or 7\% (Figure 1). The option of subscribing to more than one operator has been included when entering the data, and 14 respondents or $5 \%$ have selected it. The following diagram shows the number of respondents for each of the mobile operators, as well as the number of users of more than one operator.

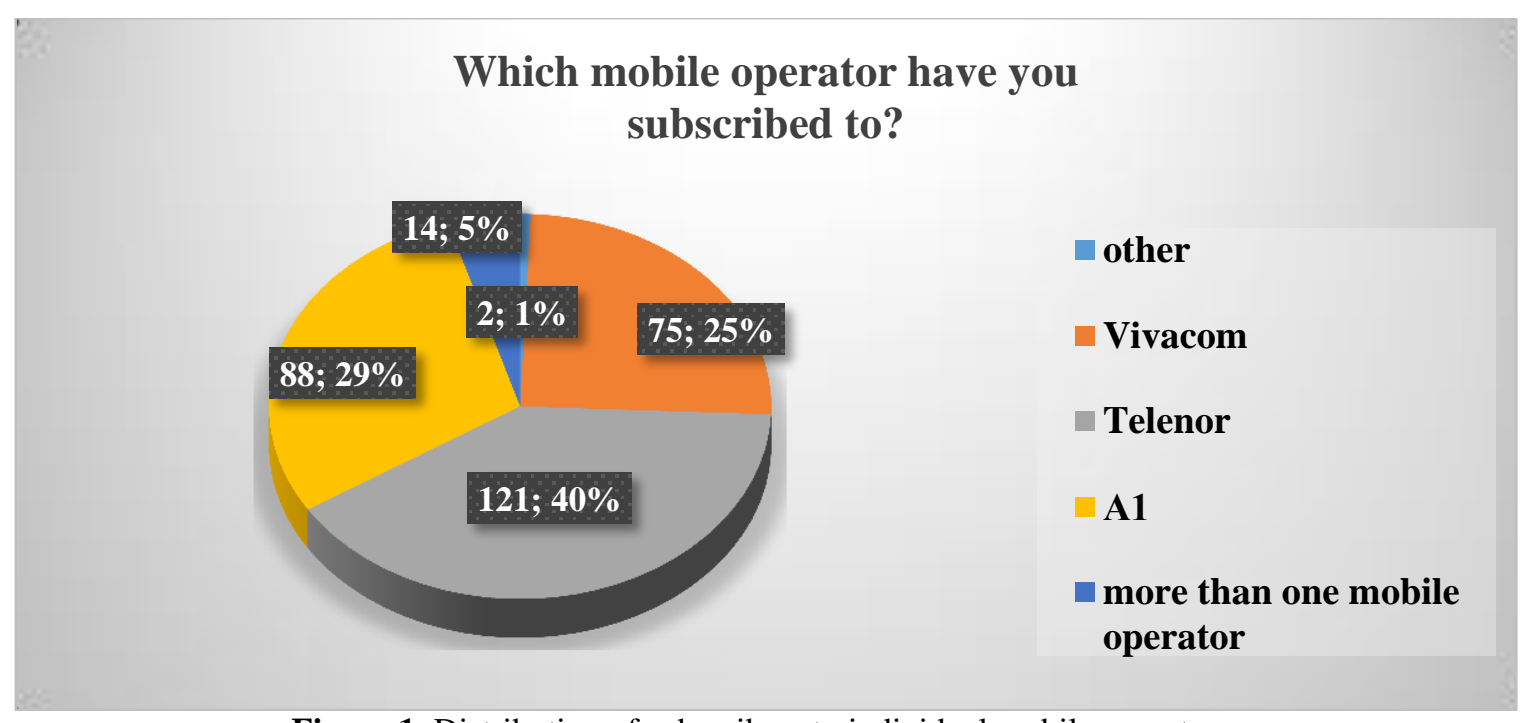

Figure 1. Distribution of subscribers to individual mobile operators.

In order to scale up the real influence of advertisements, and the purchasing completed after the viewing of a certain ad respondents have been asked whether they have used products and services of mobile operators after they have seen their ads. The question does not require the respondent to relate this action to the mobile operator he has subscribed to because the purchase from one of the operators does not necessarily coincide with the current company the respondent has signed a contract with. Furthermore, the next question in which the name of the operator is stated, offers three possible answers: positive, negative and "sometimes". The latter has been chosen as positive, but less frequently. The results to this question are presented in the following figure, where the initial expectations for a small number of respondents have been to make a purchase after being influenced by the publicity media of a mobile operator.

On the pie chart diagram it is evident that almost $50 \%$ or 147 young people have not made a purchase after seeing the advertisement of a mobile operator. However, to establish the reasons for making the purchase, correlation analyses of the consumer attitudes and the influencing factors have been made. 


\section{Have you used the products or services of a specific mobile operator after watching their advertisement?}

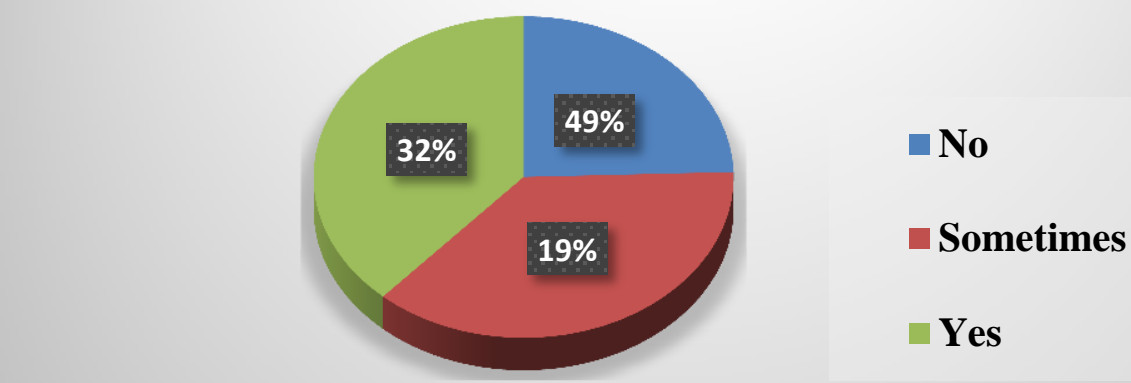

Figure 2: Purchasing behaviour under the influence of advertising.

\section{CORRELATION ANALYSES BETWEEN THE INFLUENCING FACTORS AND CONSUMER ATTITUDES AND PERSUASIONS}

Correlation analyses between the influencing factors for establishing consumer attitudes and persuasions for using products and services of mobile companies in Bulgaria have been made. The first statistically significant correlational dependency is between the scales of the two emerging opposing factors: "Plentitude of information" and "Interest in advertisement", where $r=0.303 ; p<0.01$. This means that the correlational dependency is weak. The statements valid for both scales "Plentitude of information" (items: Provides correct information to clients; Provides enough benefits for clients; Provides innovative ideas for clients) and "Interest in advertisement" (items: The ads are interesting; The ads are funny; and the reverse statement The ads are boring and monotone) can be explained through a positive correlation due to the better service of mobile operators, which has led to influencing some of the advertisements of the mobile operators. The significance of this correlation is crucial to the study because according to the first hypothesis the consumer attitudes are relatively stable and their state of being influenced or changed is very hard to achieve. According to the final result the plentitude of information and the interest in advertisement may lead to attitudinal change, as well as to inciting an interest in the products and services of the mobile operators in Bulgaria. Therefore, the richer the information in advertisements, the higher the likelihood for increasing the interest in them is, and hence in the products and services of mobile operators.

\section{Summary:}

Factor "Plentitude of information" vs factor

"Interest in advertisement" (positive statements), where $r=0.303, p<0.01$

The results of the second correlation which is weak to moderate statistically significant and has been formed by the scales of the two opposing factors: "Plentitude of information", and "Positive emotions under the influence of advertisement" where $r=0.299, p<0.01$. It shows that the high values on one of the scale correspond to the high values in the second. When comparing the statements related to the scale "Plentitude of information" (items: Provides correct information to the clients; Provides enough benefits to clients; Provides innovative ideas to clients) and the scale "Positive emotions in advertising influence" (items: Have you ever felt satisfied with the advertisements of a mobile operator? Have you ever felt excited at the advertisements of a mobile operator? Have you ever felt enthusiastic about the advertisements of a mobile operator? Have you ever felt amused by the advertisements of a mobile operator?), we can conclude that the positive correlation may be explained by the positive emotions which are incited by the advertizing of mobile operators. After the attitudinal change, and the advertising influence the respondents have noted a higher degree of positive emotions, which has led to positive attitudes. This shows a greater satisfaction in youth after making what they think are the right decisions. Therefore, mobile operators can build positive emotional attitudes in their young users through advertisement. 


\section{Summary:}

Factor "Plentitude of information"

vs factor "Positive emotions during the influence of advertisement",

where $r=0.299, p<0.01$

The results show a moderate statistically significant positive correlation between the scales of the two emerging opposing factors: "Plentitude of information" and "Building of trust in the company through benefits", where $r=0.442 ; p<0.01$. This means that there is a tendency the high values on one of the scales to correspond to the high values on the other. When comparing the statements on both scales: "Plentitude of information" (items: Provides correct information to clients; Provides enough benefits for clients; Provides innovative ideas to clients) and "Building of trust in the company through benefits" (items: Offers low prices; Offers appropriate products and services; Attends to clients' needs with care; Provides enough benefits to clients) we can establish through the positive correlation that the attitudinal change in respondents is due to improved services of mobile operators. This is the reason why respondents have a higher trust in them, which leads to giving a higher evaluation of the respective advertisment. Therefore, most positive answers provided by respondents for the first factor lead to a higher final evaluation of the companies.

\section{Summary:}

Factor "Plentitude of information" vs factor "Building of trust in the company through benefits",

where $r=0.442, p<0.01$

The results show a moderate statistically significant positive correlation between the scales of the two emerging opposing factors: "Plentitude of information" and "Reasons for purchasing a product", where $\mathrm{r}=0.359$; $\mathrm{p}<0.01$. This means that there is a tendency for the higher values on one of the scales to correspond to higher values on the other. When comparing the statements of the two scales "Plentitude of information" (items: Provides correct information to clients; Provides enough benefits to clients; Provides innovative ideas to clients) and "Reasons for purchasing a product" (items: Package services; Professional service; Fast communication; Advantages of advertized products and services; Trendy offers; The pleasure to own something new; The feeling that I am just like my peers) through which we have attempted to
SPASOVA L., et al. study the motivation for youth's behaviour, we conclude through positive correlation that attitudinal change in respondents may lead to changes in their behaviour, i.e. for making a purchase under the influence of advertisements of the operator of their choice. Therefore, most positive answers provided by respondents for the first factor will lead to finding out more reasons for behavioral changes, which is in support of the second hypothesis - the change in the beliefs of young people reflects on the change in their behaviour when using products and services of mobile operators in Bulgaria.

\section{Summary:}

Factor "Plentitude of information"

vs factor "Reasons for purchasing a product",

where $r=0.359, p<0.01$

The results show a moderate statistically significant positive correlation between the scales of the two emerging opposing factors: "Reasons for greater attention" and "Reasons for purchasing a product", where $\mathrm{r}=0.308, \mathrm{p}<0.01$. Therefore, the higher values on one of the scales correspond to the higher values of the other. As we compare the statements of the two scales - "Reasons for greater attention" (items: When prices fall; When products have more attractive features; When the specific product/service is named; When there is a demonstration of products; When the ad is aired in combination with other media products (TV show, film, news, internet), and "Reasons for making a purchase" (items: Package services; Professional service; Fast communication; Advantages of advertized products and services; Trendy offers; The pleasure to own something new; The feeling that I am just like my peers) through which the motivation for the behaviour of youth is studied, we can conclude through a positive correlation that the reasons for the greater attention of the respondents to the advertisements of mobile operators could create reasons for making a purchase, i.e. a behavioral change is observed.

Therefore, the use of serious arguments in advertisements lead to a behavioral change in young consumers, whereas the influence is exercised through central and peripheral route. Thus, it becomes clear that most positive answers by respondents for the first factor will lead to finding more reasons for behavioral change. 


\section{Summary:}

Factor "Reasons for greater attention"

vs factor "Reasons for purchasing a

product",

where $\mathrm{r}=0.308, \mathrm{p}<0.01$

The results show a moderate statistically significant positive correlation between the scales of the two emerging factors: "Positive emotions under the influence of advertisement", and "Building of trust in the company through benefits", where $r=0.382$, $\mathrm{p}<0.01$. This means that there is a tendency for the higher values on one of the scales to correspond to higher values on the other. As we compare the statements for the two scales "Positive emotions under the influence of advertisement" (items: Have you ever felt satisfied with the advertisements of a mobile operator?; Have you ever felt excited at the advertisements of a mobile operator?; Have you ever felt enthusiastic about the advertisements of a mobile operator?; Have you ever felt amused by the advertisements of a mobile operator?), and "Building of trust in the company through benefits" (items: Offers low prices; Provides appropriate products and services; Attends to clients' needs with care; Provides enough benefits to clients) we conclude that positive emotions, as well as the attitudes of the young respondents would lead to building greater trust in the mobile operator of their choice. This is directly related to the value system of the young generation aged 18 to 25 , whose trust and good intentions noted while conducting the survey, reveal social security, harmony and stability for each young person.

\section{Summary:}

Factor "Positive emotions under the influence of advertisement"

vs factor "Building of trust in a company through benefits",

where $r=0.382, p<0.01$

The results show a moderate statistically significant positive correlation between the scales of the two emerging factors: "Perception of products and services", and "Reasons for purchasing a product", where $\mathrm{r}=0.313, \mathrm{p}<0.01$. This means that there is a tendency the high values on the one scale to correspond to high values on the other. As we compare the statements for the two scales "Perception of products and services" (items: To receive cheaper package services; To use specific products and services; To incite an enduring wish for using products and services),
SPASOVA L., et al. and "Reasons for purchasing products" (items: Package services; Professional service; Fast communication; Advantages of advertized products and services; Trendy offers; The pleasure to own something new; The feeling that I am just like my peers) we can conclude that partial or complete perception of the products and services of the mobile operator chosen by the respondent can create reasons for purchasing these products and services. Therefore, the greater acceptance of the products under the influence of advertisement to a greater extent would change the young person's behaviour.

\section{Summary:}

Factor "Perception of products and services" vs factor "Reasons for purchasing a product",

where $\mathrm{r}=0.313, \mathrm{p}<0.01$

\section{INFERENCES}

1) Young people's perception of the different products and services provided by mobile operators in Bulgaria is influenced by advertisements.

2) Changes in consumers' attitudes are hard to investigate, but the continuity of the study shows evidence of such.

3) The establishment of enduring beliefs in respondents is another complex responsibility of the mobile companies which is measured through advertising influence.

4) The behavioral change in youth between 18 and 25 years of age can be explained with the partial or complete perception of the products and services of the Bulgarian mobile operators.

These conclusions confirm the proposed hypotheses to a certain extent.

\section{CONCLUSION}

The study of human attitudes is of crucial importance for setting preliminary expectations of consumers, as well as finding different impulses and inhibitions in various individuals. The different types of attitudes determine human behaviour. However, researchers have discovered a change in the attitudes which can be explained with creating a situation, continuous influence or designing conditions for new attitudes. This situation is provoked by advertising campaigns of mobile operators in Bulgaria.

The persuasive influence of advertisement is a complex and long process in which perception, 
processing of advertising information and in rare cases - a change in consumer behavior have been observed. The quality of advertizing communication depends on the main features of its impact. To investigate the aspects of the persuasive influence of advertizing communication promulgated by mobile operators in Bulgaria, the extended model of persuasive influence is applied. It allows different stimulants on consumers to be observed and the formation of attitudes leading to their final reactions to be noted. The behavioral change in young people at the age of 18 to 25 years is explained with the partial or complete perception of products and services provided by mobile operators in Bulgaria.

\section{REFERENCES}

1. Crespi, I., The Public Opinion Process. How People Speak. $1^{\text {st }}$ edition, N.Y.; p. 8789., 1998.

2. Cutlip, S. et al., Effective Public Relations. NJ: ROI Communication, p.187, 2010.
SPASOVA L., et al.

3. Dilova, M. Nikova, G. Dictionary of Psychology, Sofia, p. 300-302, 1989.

4. Doganov, D., Palfi, F. What is Advertisement, Sofia: Princeps, p.181, 1999.

5. Festinger, L., A theory of cognitive dissonance. Evanston IL: Row, Peterson, p. 117-140, 1957.

6. Hristov, Ch. Persuasion and Influence, Sofia: SIELA, p. 65, 2008.

7. Minchev, B. Psychology. Evolutionary Phenomenological Approach. Sofia: SIELA, p.68, 2013.

8. Myer, D., Social Psyhology, $7^{\text {th }}$ edition, McGraw-Hill, Boston., p.290, 2002.

9. Petrova, A. Psychology of the Advertisement, Sofia: ForKom, p. 53, 1999.

10.Petty, R., Cacioppo, J. Communication and Persuasion: The Central and Peripheral Routes to Attitudinal Change. New York: Spring-Verlag, p. 578, 1986.

11.Zimbardo, P., Leippe, M.,The Psychology of Attitudinal Change and Social Influence. New York: McGraw-Hill, p.173, 1991. 